\title{
A Dire Consequence of Extensive Oral Squamous Cell Carcinoma- A
}

\section{Case Report}

\section{Ashaya M*, Raghavendra Kini, Prasanna Kumar Rao J, Gowri B, Roopashri K and Devishree R \\ Department of Oral Medicine \& Radiology, AJ Institute of Dental Sciences, India}

*Corresponding author: Ashaya M, Department of Oral Medicine \& Radiology, AJ

Institute of Dental Sciences, Mangaluru 575004, Karnataka, India, ashayaupadhya@gmail.com

\section{Image Article \\ Volume 3 Issue 4}

Received Date: September 24, 2018

Published Date: October 01, 2018

DOI: $10.23880 /$ oajds-16000197

Tel: +917899497464; Email:

\section{Abstract}

Squamous cell carcinoma of alveolar ridge is an uncommon lesion. Early treatment assures better prognosis while negligence can lead to hazardous, undesired consequences. Lack of awareness, failure to receive early treatment can lead to extensive lesion and undesirable complication like pathological fracture of mandible. This is an article which reports a case of long standing malignancy of edentulous mandibular alveolar ridge with highlights on clinical features, treatment options for such an extensive lesion.

Keywords: Squamous cell carcinoma; Mandibular alveolar ridge; Ulceroproliferative growth; Orthopantomogram

\section{Introduction}

A 42 year old male patient came with the chief complaint of swelling in the lower jaw since 4 months. Swelling markedly increased since 20 days. H/O exfoliation of three teeth in past 6 months. Swelling was associated with mild pain. Past medical and dental history was non contributory. Patient's maternal uncle had oral cancer. Patient gave a history of tobacco chewing since 8 years, 2 to 3 times per day. Extraoral examination revealed presence of diffuse swelling involving lower 3rd of the face on right side extending superiorly till the level of ala tragal line, inferiorly extending $2 \mathrm{~cm}$ below the inferior border of mandible, medially from the ala till the angle of mandible (Figure 1). Hard and firm in consistency on palpation. Bilateral submandibular, submental and upper jugular lymphnodes were palpable, hard in consistency and non tender.

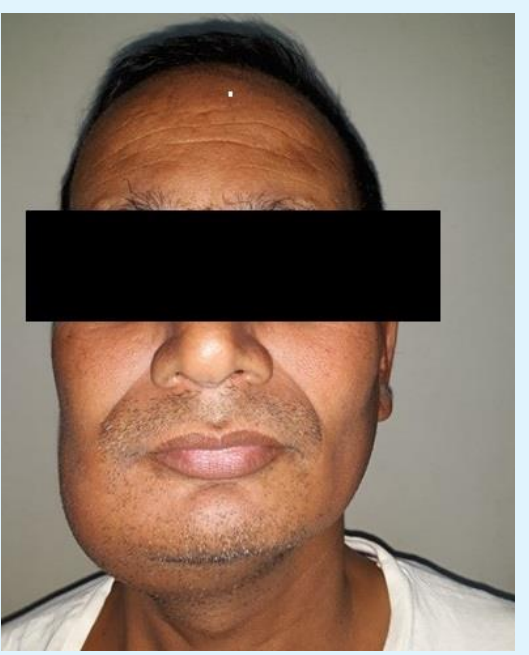

Figure 1: Extraoral photograph. 
Intraoral examination revealed a ulceroproliferative growth (Figure 2) on right side of lower jaw extending from midline till retromolar region involving entire edentulous alveolar ridge with indistinct border. Surface of the erythematous granular mass was corrugated, irregular and covered with necrotic slough. Spontaneous bleeding was seen. White keratotic patch seen in right lower buccal vestibule extending from the region of 33 till the retromolar region with cracked mud appearance (Figure 3). On palpation, the findings of inspection were confirmed. The growth was non tender, surrounding tissue was indurated. Provisional diagnosis of malignancy of right mandibular alveolus and homogenous leukoplakia in right lower buccal vestibule was given.

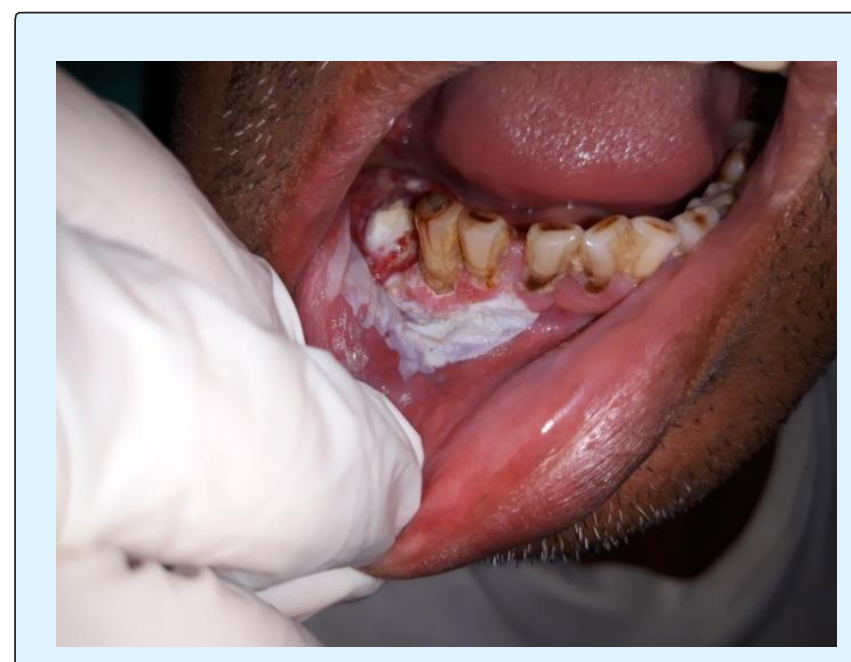

Figure 2: Intraoral image showing well define homogenous white patch in buccal vestibule extending to buccal mucosa.

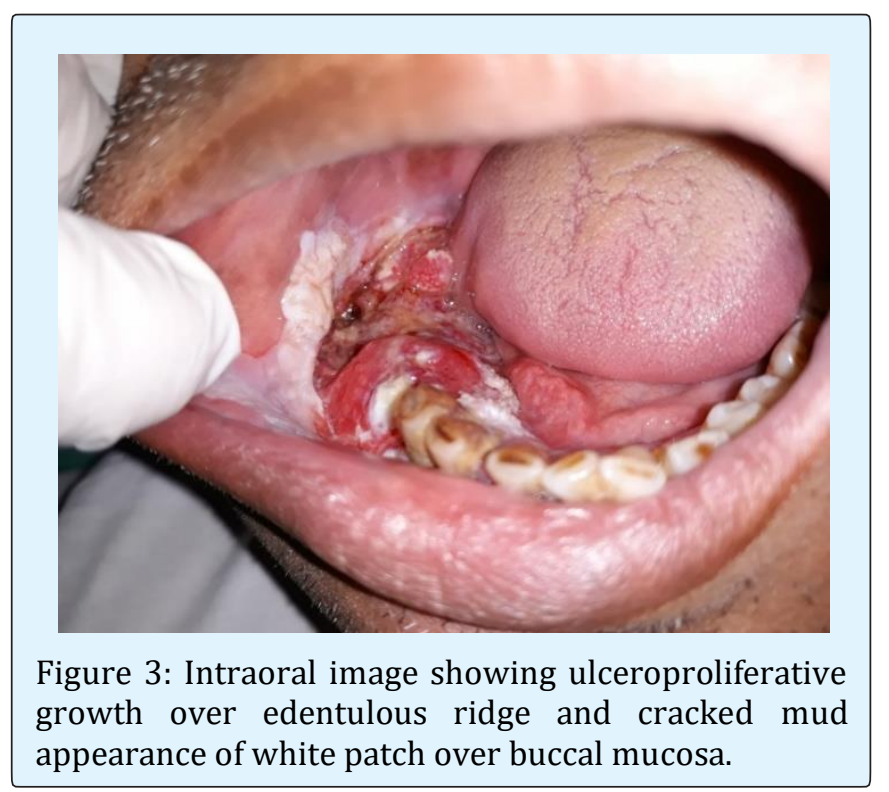

Orthopantomogram revealed radiolucency in right body of mandible extending from canine region to retromolar region with irregular ragged border and moth eaten appearance extending to inferior border of mandible which appears to have discontinuity and step deformity suggestive of pathologic fracture. Biopsy and histopathological examination concluded the lesion to be well differentiated squamous cell carcinoma of right mandibular alveolus (Figure 4).

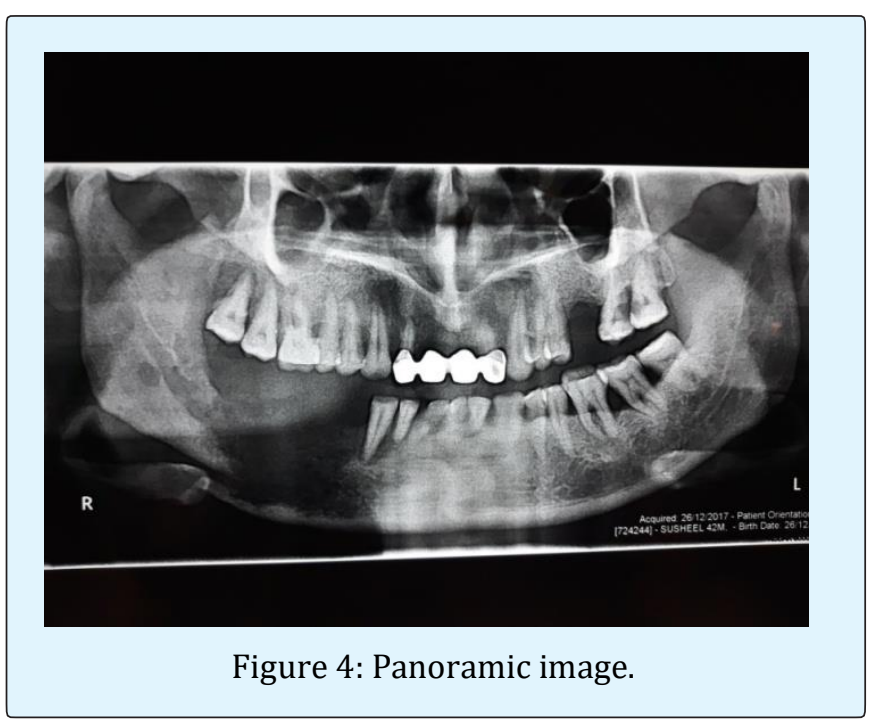

Patient was advised to quit the deleterious habit and was referred to department of oral surgery and oncology for further evaluation and treatment. Squamous cell carcinoma of alveolar ridge is an uncommon lesion [1] usual sites being tongue, buccal mucosa, labial mucosa [2] the five year survival rate of oral squamous cell carcinoma is about $45-50 \%$ [3]. The rates of local control and survival are better when resection margins are positive or wide [4]. In this case better prognosis can be expected with treatment options like hemi mandibulectomy with wide excision or combined segmental therapy [5] along with radical neck dissection. Such extensive lesion inspite of rapid growth and aggressiveness and undesired complication like pathologic fracture of mandible couldn't stop the patient from quitting tobacco and undergo treatment suggests the lack of awareness among general population regarding the adverse effects of tobacco, cancer, self examination, early detection and treatment.

\section{References}

1. Ildstad ST, Bigelow ME, Remensnyder JP (1984) Squamous cell carcinoma of the alveolar ridge and palate. A 15-year survey. Ann Surg 199(4): 445-453. 


\section{Open Access Journal of Dental Sciences}

2. Keser G, Pekiner FN, Ozbayrak S, Alatli C (2015) Squamous cell carcinoma of the gingiva: a case report and literature review. Clinical and Experimental Health Sciences 5(4): 290-295.

3. Seneift HA, Celebiler O (2004) Squamous cell carcinoma of the mandibular alveolar ridge. OHDMBSC 3(3): 27-30.
4. Shingaki S, Nomura T, Takada M, Kobayashi T, Suzuki I, et al. (2002) Squamous cell carcinomas of the mandibular alveolus: analysis of prognostic factors. Oncology 62(1): 17-24.

5. Wald RM, Calcaterra TC (1983) Lower alveolar carcinoma: segmental $\mathrm{v}$ marginal resection. Arch Otolaryngol 109(9): 578-582.

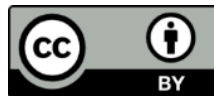

